\title{
Controle abstrato e concentrado de constitucionalidade comparado (Brasil, Portugal e Angola) e seus efeitos nas instituições sociais ejurídicas
}

Comparative Abstract and Concentrated Judicial Review (Brazil, Portugal and Angola) and its Effects in Social and Law Institutions

Controlo Abstracto y Concentrado de Constitucionalidad Comparado (Brasil, Portugal y Angola) y sus efectos en las Instituciones Sociales y Jurídicas

Fabricio Ricardo de Limas Tomio* Ilton Norberto Robl Filho**

\section{Resumo}

Este artigo analisa, empírica e comparativamente, as decisões dos Tribunais Constitucionais de Portugal e de Angola e do Supremo Tribunal Federal brasileiro no controle concentrado/abstrato, verificando a validade empírica de duas hipóteses sobre o abstract judicial review: 1) a proposição sobre a regra da absorção (TSEBELIS, 2009), com tribunais não atuando contramajoritariamente ao decidir sobre legislação aprovada pela coalizão majoritária, e 2) nas decisões que envolvem atores de diversos níveis governamentais (BZDERA, 1993), se o controle abstrato restringe a descentralização a partir de prerrogativas consolidadas constitucionalmente pelo poder central. Conclusões preliminares indicam validade empírica da primeira hipótese no
Brasil e da segunda hipótese no Brasil e em Portugal. Em Angola, a segunda hipótese é completamente negada.

Palavras-chave: Judicialização da política comparada. Jurisdição constitucional. Controle concentrado/abstrato de constitucionalidade.

\footnotetext{
Professor Associado nos cursos de Doutorado, Mestrado e Graduação da Faculdade de Direito da Universidade Federal do Paraná (UFPR). Doutor em Ciência Política pela Universidade de Campinas (UNICAMP). E-mail: fab_tom@hotmail.com.

** Professor Adjunto na Graduação da Faculdade de Direito da UFPR e no Programa de Mestrado em Direito da Universidade de Passo Fundo (UPF). Doutor em Direito pela UFPR. Diretor da Academia Brasileira de Direito Constitucional (ABDConst). E-mail: norbertorobl@gmail.com.
}

Recebido em 04/05/2015 - Aprovado em 05/05/2015 http://dx.doi.org/10.5335/hdtv.15n.1.5284 


\section{Introdução}

Este artigo $^{1}$ tem por objeto o judicial review (controle judicial de constitucionalidade) como parte do processo decisório/ legislativo e seus determinantes pelo arranjo das instituições políticas e das relações entre os poderes. Em especial, abordamos comparativamente as decisões dos Tribunais Constitucionais de Portugal e de Angola e do Supremo Tribunal Federal brasileiro no controle concentrado/abstrato de constitucionalidade de leis nos períodos constitucionais recentes: 1) Ações diretas de inconstitucionalidade, no Brasil (1988-2013); 2) Fiscalização abstrata sucessiva, em Portugal (1983-2013) e 3) Fiscalização sucessiva, em Angola (20112014).

As questões centrais tratadas são as seguintes: como abordar o controle concentrado/abstrato de constitucionalidade como parte do processo decisório, tendo as regras institucionais como variáveis explicativas do processo? Qual a extensão efetiva do controle concentrado/abstrato sobre o processo decisório? Os Tribunais Constitucionais vetam decisões dos atores políticos indistintamente ou suportam as decisões tomadas pelas coalizões de governo? Os efeitos do controle concentrado/abstrato de constitucionalidade sobre o processo decisório/legislativo variam nesses países?

\section{Tribunais Constitucionais no}

\section{processo decisório/legislativo: 0}

controle abstrato/concentrado de

\section{constitucionalidade comparado}

\author{
Questões preliminares: 0 papel dos \\ Tribunais Constitucionais nas democracias \\ constitucionais contemporâneas
}

Há óbvios laços históricos e culturais entre Portugal, Brasil e Angola em virtude da colonização portuguesa, a qual marcou de forma indelével a construção das instituições, da sociedade civil e do direito brasileiro e angolano ${ }^{2}$. De outro lado, neste artigo, a questão do estabelecimento de instituições democráticas constitucionais recentes nesses três países recebe maior relevância.

Observam-se as transições de governos autoritários em Portugal de 1926 a 1974 e, no Brasil, de 1964 a 1985 para democracias constitucionais, assim como a construção do estado democrático de direito em Angola após intensa guerra de independência de 1961 a 1975 e depois de guerra civil de 1975 a 2002. Em um primeiro momento, a questão do estabelecimento de eleições livres, plurais e democráticas e da promoção de liberdades cívicas básicas recebe destaque na estruturação de jovens democracias.

De outro modo, com o advento das Constituições democráticas, o tema do controle judicial de constitucionalidade passa a ser relevante. Fundam-se estruturas jurídicas e políticas, as quais são garantidas pelo $j u$ dicial review. ${ }^{3}$ Por sua vez, Brasil, Portugal e Angola fixaram o controle judicial de constitucionalidade abstrato e concentrado, o qual é objeto de análise comparada neste artigo. 
Abordagem

A literatura brasileira acumulou, na última década, um conhecimento descritivo e, eventualmente, analítico sobre a participação do Supremo Tribunal Federal (STF) no processo decisório, por meio do estudo dos julgamentos de milhares de Ações Diretas de Inconstitucionalidade (ADIs) em variados aspectos (VIANNA; BURGOS; SALLES, 2007; CARVALHO, 2009; TAYLOR; DA ROS, 2008; TOMIO; ROBL, 2013). Também são encontrados estudos comparados sobre o padrão decisório dos Tribunais Constitucionais em judicial review (BZDERA, 1993; VANBERG, 1998, 2001; FIGUEROA; TAYLOR, 2006; CORKIN, 2010).

Entretanto, são escassos os estudos que comparam o STF ${ }^{4}$ e os Tribunais Constitucionais com controle abstrato/concentrado de constitucionalidade no processo decisório, buscando dimensionar e explicar a judicialização da política brasileira em uma perspectiva empírica e comparada. Este é o objetivo fundamental deste estudo: determinar o papel do controle judicial abstrato de constitucionalidade e a extensão desse controle comparativamente, utilizando como base empírica as decisões dos Tribunais Constitucionais.

Na construção da abordagem teórico-metodológica, analisamos o abstract judicial review como um efeito contingente das estratégias dos atores políticos/institucionais em um processo decisório modelado por instituições (como regras do jogo decisório), isto é, o papel institucional e a atuação do judiciário no processo decisório democrático. Além disso, a questão central do estudo en- volve: a judicialização e os poderes e prerrogativas institucionais atribuídos aos Tribunais Constitucionais no controle judicial de constitucionalidade para a construção das hipóteses sobre a judicialização do processo decisório.

Ao abordar o processo decisório judicializado, tratamos o processo de construção de decisões como um conjunto de interações entre atores institucionais (individuais e coletivos) que produzem determinado conjunto de resultados políticos (policy outcomes), dependentes da variação institucional e de variáveis políticas que envolvem os desejos/crenças dos atores envolvidos em uma interação estratégica. Não há, portanto, uma definição substantiva de instituição política na abordagem deste estudo.

As evidências empíricas e as conclusões que permitem especificar o papel do controle judicial de constitucionalidade e a extensão do controle concentrado/abstrato de constitucionalidade utilizam como base as decisões dos três tribunais constitucionais em cerca de seis mil ações de constitucionalidade. Em verdade, o estudo proposto busca verificar a validade empírica de duas hipóteses presentes na literatura sobre $o$ abstract judicial review:

1) a proposição sobre a regra da absorção (TSEBELIS, 2009), na qual os tribunais não são atores com poder de veto, porque são absorvidos pelos outros veto players (governo, parlamentos, partidos), logo não agem contramajoritariamente ao decidir em controle abstrato sobre legislação aprovada pela coalizão majoritária. ${ }^{5}$ As variáveis explicativas (independentes) dessa proposição são: (i) variáveis 
institucionais (extensão dos legitimados requerentes, tipos de ações, mandato/ forma de nomeação, etc.), (ii) variáveis políticas (composição parlamento/governo, coalizões, estabilidade decisória, nomeações para cortes, posição do governo/maioria parlamentar sobre a constitucionalidade/inconstitucionalidade da lei). E, as variáveis dependentes são as decisões em controle concentrado/ abstrato. De forma geral, as hipóteses a serem testadas seriam as seguintes:

H1A - A probabilidade de o Tribunal Constitucional vetar legislação aprovada pela coalizão (governo/ maioria parlamentar) via controle abstrato iniciado pela minoria (oposição partidária e/ou grupos de interesse) declina quanto maior a absorção da mediana dos membros do Tribunal Constitucional devido aos critérios institucionais de nomeação.

H1B - A probabilidade de o Tribunal Constitucional vetar legislação aprovada por maiorias geradas por deserções da coalizão via controle abstrato, iniciado por atores políticos (partidos e/ou grupos de interesse) ou por atores institucionais (procuradorias, governos, parlamentos, etc.), aumenta quanto maior a absorção da mediana dos membros da suprema corte devido aos critérios institucionais de nomeação.

2) para tratar das decisões que envolvem atores de diversos níveis governamentais, verificar-se-á a validade da propo- sição de Bzedera (1993) que, basicamente, sustenta que o controle abstrato de constitucionalidade tem como objetivo restringir a federação/descentralização a partir de dispositivos/prerrogativas consolidados/as constitucionalmente pelo poder central. Aqui são incluídas as variáveis institucionais de distribuição de competências entre os níveis de governo e uma variável dummie sobre as decisões que envolvem o controle federativo/descentralização. A hipótese:

H2 - Os aspectos institucionais do arranjo federativo/relações intergovernamentais e de suas instituições judiciais (notadamente, seleção e composição) aumentam a probabilidade de os Tribunais Constitucionais promoverem a centralização política, na medida em que não impedem as iniciativas legislativas centralizadoras do governo central e limitam as iniciativas dos governos locais/das unidades federadas.

As hipóteses H1A e H1B são mais abrangentes. Abordam todas as decisões judiciais, independentemente do requerente da ação. Ou seja, o pressuposto é de que a forma de nomeação dos juízes de cortes constitucionais, responsáveis pela solução dos conflitos abstratos sobre a validade de norma legislativa, aproximará as preferências da maioria parlamentar (coalizão de governo) das posições da maioria da corte constitucional (regra da absorção). Em virtude disso, seria baixa a expectativa de a corte vetar (tornar nula) uma norma (lei, lei orgânica, decreto-lei, etc.) aprovada pela maio- 
ria, por requerimento de atores minoritários (partidos e/ou organizações sociais).

Complementarmente, o próprio controle abstrato/concentrado de constitucionalidade poderia ser utilizado pela coalizão majoritária, por meio de atores políticos (partidos e/ou grupos de interesse) ou institucionais (procuradorias, governo, etc.), como um instrumento para vetar legislação aprovada por deserções na maioria parlamentar. No Quadro 1, esse tipo de processo decisório judicializado é identificado como intraunidade, quando tanto o requerente quanto a norma pertencem ao mesmo nível do Estado. Neste texto, particularmente, interessa-nos prioritária e comparativamente o conflito que se estabelece no nível federal/ nacional.

Quadro 1: Conflito de constitucionalidade judicializado em controle abstrato e concentrado (federativo/intraunidade) - por origem da norma questionada como inconstitucional e do requerente da ação de inconstitucionalidade

\begin{tabular}{|c|c|c|c|}
\hline & \multicolumn{2}{|c|}{ Norma } \\
\hline & & $\begin{array}{l}\text { Federal/ } \\
\text { nacional }\end{array}$ & $\begin{array}{l}\text { Estadual/ } \\
\text { regional }\end{array}$ \\
\hline \multirow{2}{*}{ Requerente } & $\begin{array}{l}\text { Federal/ } \\
\text { nacional }\end{array}$ & Intraunidade & $\begin{array}{c}\text { Conflito } \\
\text { federativo }\end{array}$ \\
\hline & $\begin{array}{l}\text { Estadual/ } \\
\text { regional }\end{array}$ & $\begin{array}{l}\text { Conflito } \\
\text { federativo }\end{array}$ & Intraunidade \\
\hline
\end{tabular}

Fonte: Elaboração dos autores.

A hipótese H2 é mais específica e trata dos conflitos federativos, quando o requerente da judicialização e a norma judicializada não pertencem ao mesmo nível do Estado. De certa forma, esse tipo de conflito poderia ser analisado como parte do processo decisório anterior. Ou seja, pela regra da absorção, aumentaria a probabilidade da corte constitucional responder favoravelmente às demandas e/ou não nulificar a norma do nível do Estado, responsável pela nomeação dos juízes, em geral, o nível mais central do Estado.

Nas federações e estados unitários com algum grau de descentralização (federacies), a existência de pelo menos dois níveis de governo com atribuições definidas constitucionalmente suscita a questão sobre quem será $\mathrm{o}$ árbitro quando as unidades componentes entrarem em conflito. A instituição do controle abstrato de constitucionalidade tornou a corte constitucional como principal (e definitivo) árbitro das disputas federativas.

O efeito do controle abstrato de constitucionalidade, assim, pode ser interpretado como "centralização" ou "descentralização", conforme governos central e regional obtenham sucesso nas suas iniciativas. $\mathrm{O}$ resultado esperado desse processo decisório seria o favorecimento do processo legislativo da unidade mais central do Estado.

Apesar de Portugal e de Angola serem Estados unitários, há expressas previsões constitucionais com respeito a determinadas autonomias dos governos subnacionais, nos termos do art. $6^{\circ}, 225,228,241$ e 288, da Constituição da República Portuguesa e do art. $8^{\circ}, 201$ e 213 a 225, da Constituição da República de Angola. Desse modo, este texto analisará se o controle judicial abstrato de constitucionalidade tem um impacto maior na garantia das autonomias locais/regionais nesses países ou na manutenção da centralização do poder. 
Regras institucionais: nomeação dos juízes e requerentes

Para a determinação da absorção dos juízes dos tribunais pelas maiorias/coalizões de governo e para determinar a possibilidade e volume de conflitos jurisdicionalizados, alguns parâmetros institucionais (variáveis independentes) são comparados: extensão dos legitimados requerentes e o mandato/ forma de nomeação dos juízes. Quanto aos legitimados requerentes, definimos a possibilidade de jurisdicionalizar o processo decisório como amplo, restrito ou inexistente, tendo como parâmetro a quantidade de legitimados (institucionais, partidários/parlamentares e sociais), o tamanho da minoria parlamentar (partidos) necessária ao requerimento e as limitações quanto ao escopo da norma judicializada.

Quadro 2: Legitimados requerentes (no controle abstrato e concentrado)

\begin{tabular}{|c|c|c|}
\hline País & Requerimento & Legitimados (definição constitucional) \\
\hline Brasil & $\begin{array}{l}\text { Amplo para instituições, partidos e or- } \\
\text { ganizações sociais } \\
\text { Sem restrições no tempo (possibilida- } \\
\text { de de atacar todos os atos normativos } \\
\text { posteriores à Constituição) e única res- } \\
\text { trição ao escopo da demanda de orga- } \\
\text { nizações sociais }\end{array}$ & $\begin{array}{l}\text { Presidente da República; Mesa do Sena- } \\
\text { do Federal; Mesa da Câmara dos Deputa- } \\
\text { dos; Mesa de Assembleia Legislativa; Go- } \\
\text { vernador de Estado; procurador-geral da } \\
\text { República; conselho federal OAB; partido } \\
\text { político com representação no Congresso } \\
\text { Nacional; confederação sindical ou entida- } \\
\text { de de classe de âmbito nacional. }\end{array}$ \\
\hline Portugal & $\begin{array}{l}\text { Amplo para instituições e pequenas } \\
\text { minorias (10\%) } \\
\text { Restrito para os legitimados das comu- } \\
\text { nidades autônomas, quanto ao escopo } \\
\text { da ação }\end{array}$ & $\begin{array}{l}\text { Presidente da República; Presidente da } \\
\text { Assembleia da República; Primeiro-Minis- } \\
\text { tro; Provedor de Justiça; Procurador-Geral } \\
\text { da República; Um décimo dos deputados } \\
\text { da Assembleia da República; representan- } \\
\text { tes da República, de Assembleias Legisla- } \\
\text { tivas das regiões autônomas, presidentes } \\
\text { das Assembleias Legislativas das regiões } \\
\text { autônomas, presidentes dos governos re- } \\
\text { gionais ou um décimo dos deputados da } \\
\text { respectiva Assembleia Legislativa (quando } \\
\text { o pedido de declaração de inconstituciona- } \\
\text { lidade se fundar em violação dos direitos } \\
\text { das regiões autônomas ou o pedido de de- } \\
\text { claração de ilegalidade se fundar em viola- } \\
\text { ção do respectivo estatuto). }\end{array}$ \\
\hline Angola & $\begin{array}{l}\text { Amplo para instituições e pequenas } \\
\text { minorias }(10 \%) \\
\text { Inexistente para governos ou repre- } \\
\text { sentantes regionais }\end{array}$ & $\begin{array}{l}\text { Presidente da República; um décimo dos } \\
\text { deputados da Assembleia Nacional em efe- } \\
\text { tividade de funções; os grupos parlamen- } \\
\text { tares; o procurador-geral da República; o } \\
\text { provedor de justiça; a ordem dos Advoga- } \\
\text { dos de Angola (OAA). }\end{array}$ \\
\hline
\end{tabular}

Fonte: Angola (2010); Brasil (1988); Portugal (1976); Supremo Tribunal Federal; Tribunal Constitucional da República de Angola; Tribunal Constitucional de Portugal. 
Como descrito no Quadro 2, o número de requerentes é mais amplo no Brasil, o que favorece uma maior litigância em controle abstrato de constitucionalidades. Em Portugal e em Angola, o acesso ao requerimento é amplo, inclusive para pequenas minorias parlamentares $(10 \%)$, mas o acesso aos legitimados das comunidades autônomas é restrito em Portugal e inexistente aos governos locais em Angola.
Quanto aos requisitos constitucionais para mandato/forma de nomeação dos juízes dos Tribunais Constitucionais (ver Quadro 3), definimos três indicadores: tamanho, nomeação e mandato. O tamanho dos tribunais apresenta pequena variação (11 no Brasil, 13 em Portugal e 11 em Angola) e, por si, parecem ter pouca determinação sobre o resultado da decisão.

Quadro 3: Membros, nomeação e mandato dos tribunais

\begin{tabular}{|l|l|l|l|}
\hline \multicolumn{1}{|c|}{ País } & Membros & \multicolumn{1}{|c|}{ Nomeação } & Mandato \\
\hline Brasil & 11 & $\begin{array}{l}\text { Nomeação do presidente, com aprovação pela maioria } \\
\text { do Senado Federal }\end{array}$ & $\begin{array}{l}\text { Vitalício, até } \\
\text { os } 70 \text { anos }\end{array}$ \\
\hline Portugal & 13 & $\begin{array}{l}\text { Dez, pela Assembleia da República (por dois terços pre- } \\
\text { sentes ou maioria absoluta); } \\
\text { Três, escolhidos pelos juízes eleitos para o Tribunal }\end{array}$ & 9 anos \\
\hline Angola & 11 & $\begin{array}{l}\text { Quatro juízes indicados pelo presidente da República, } \\
\text { incluindo o presidente do tribunal; quatro juízes eleitos } \\
\text { pela Assembleia Nacional, incluindo o vice-presidente } \\
\text { do Tribunal, por maioria de dois terços dos deputados; } \\
\text { dois juízes eleitos pelo Conselho Superior da Magistra- } \\
\text { tura Judicial; um juiz selecionado por concurso público } \\
\text { curricular }\end{array}$ & 7 anos \\
\hline
\end{tabular}

Fonte: Angola (2010); Brasil (1988); Portugal (1976); Supremo Tribunal Federal; Tribunal Constitucional da República de Angola; Tribunal Constitucional de Portugal.

O mandato poderia ter maior determinação sobre a possibilidade de a maioria dos juízes ter uma preferência muito discrepante em relação à maioria parlamentar, sobretudo se os ciclos das coalizões de governo e os resultados eleitorais fossem alterados de forma mais rápida do que a composição dos tribunais. Os mandatos variam de sete anos em Angola à vitaliciedade no Brasil. Entretanto, a restrição de idade no Brasil (70 anos) reduz significativamente o tempo médio dos juízes na corte.

Esses indicadores somente podem ser dimensionados tendo em vista a variação política, que necessitaria ser mensurada no período analisado. Infelizmente, os dados disponíveis, no momento, não tornam possível essa verificação para todos os tribunais, governos e parlamentos.

As regras de nomeação dos tribunais, de outro modo, permitem algumas deduções sobre o grau de absorção do tribunal constitucional pela maioria parlamentar (e coalizão de governo). Acredita-se que: a) as regras de nomeação combinadas (a maior autonomia do governo - coalizão) na indicação/ nomeação; b) a menor maioria parlamentar 
necessária para confirmação da nomeação (sobretudo em parlamentos mais fragmentados partidariamente); c) a menor quantidade de autoridades/parlamentos responsáveis pela nomeação/confirmação favoreceriam a absorção da maioria dos juízes dos tribunais.

Quanto ao conflito federativo, a probabilidade é de que todas as cortes fossem mais favoráveis ao nível central do Estado. Ignorando, neste momento, as variáveis políticas/eleitorais, poderia ser descrito dessa forma o grau de absorção previsto para as cortes constitucionais: elevado, no Brasil e em Angola, e moderado em Portugal. ${ }^{6}$
Por fim, cabe aqui ainda definir qual é o escopo de ações, requerendo a inconstitucionalidade de norma que serão analisadas nesse comparativo (ver Tabela 1). Nos diferentes Tribunais Constitucionais, há várias formas de ações abstratas que podem ser analisadas. Para citar algumas: no Brasil, além da ação direta de inconstitucionalidade, há a ação declaratória de constitucionalidade (ADC), a ação por descumprimento de preceito fundamental (ADPF) e a ação direta de inconstitucionalidade por omissão (ADO); em Portugal e em Angola existe o controle preventivo (além do sucessivo).

Tabela 1: Tribunais e tipos de ações (controle abstrato e concentrado)

\begin{tabular}{|c|c|c|c|c|}
\hline País & Tribunal & Tipo de ação & Quantidade & Período \\
\hline Brasil & Supremo Tribunal Federal & $\begin{array}{l}\text { Ação direta de inconstitu- } \\
\text { cionalidade }\end{array}$ & 4.962 & $1988 / 2013$ \\
\hline Portugal & Tribunal Constitucional & Fiscalização sucessiva & 512 & $1983 / 2013$ \\
\hline Angola & $\begin{array}{l}\text { Tribunal Constitucional da } \\
\text { República de Angola }\end{array}$ & Fiscalização sucessiva & 6 & $2011 / 2014$ \\
\hline
\end{tabular}

Fonte: Supremo Tribunal Federal; Tribunal Constitucional da República de Angola; Tribunal Constitucional de Portugal. Base de dados organizada pelos autores.

Nota: No Brasil, excluídas as ADIs iniciadas por "pessoas físicas" e/ou que questionam normas municipais (49 ADls). Em Portugal, excluídas as ações de fiscalização preventiva (121 ações). Em Angola, excluída ação de fiscalização preventiva (1 ação).

A escolha da ação de fiscalização sucessiva de constitucionalidade em Portugal e em Angola ocorreu por ser a forma processual mais semelhante à ação direta de inconstitucionalidade, julgada pelo STF no Brasil. Ou seja, aquela tem o efeito direto de tornar nula abstratamente uma norma aprovada pelos parlamentos.
Análise empírica do Tribunal Constitucional de Angola ${ }^{7}$

O Tribunal Constitucional de Angola julga as seguintes ações e recursos: a) fiscalização preventiva de constitucionalidade; b) fiscalização sucessiva de constitucionalidade; c) processo de consulta sobre a concretização da Constituição; d) recurso extraordinário de inconstitucionalidade; e) recurso ordinário de inconstitucionalidade; f) partido/candidatura; g) outras ações e recursos. No período de 2008 a 2014, o Tribunal Constitucional julgou seis ações de fiscalização sucessiva, descritas na Tabela 2. 
Tabela 2: Acórdãos de controle sucessivo em Angola

\begin{tabular}{|c|c|c|c|c|}
\hline Acórdão & Processo & Requerente & Resultado & Ementa \\
\hline $130 / 2011$ & 166/2010-D & OAA & Improcedente & $\begin{array}{l}\text { Processo de fiscalização sucessiva, pro- } \\
\text { movido pela Ordem dos Advogados de } \\
\text { Angola, sobre a norma do artigo } 26 \text { da } \\
\text { Lei } 7 / 1978 \text {, de } 26 \text { de maio - Lei dos Cri- } \\
\text { mes contra a Segurança do Estado. }\end{array}$ \\
\hline $136 / 2011$ & $173 / 2010$ & Deputados & Improcedente & $\begin{array}{l}\text { Processo de fiscalização sucessiva, } \\
\text { requerido pelo Grupo Parlamentar da } \\
\text { Unita, para apreciação da constituciona- } \\
\text { lidade da alínea g do artigo } 36 \text { da Lei no } \\
5 / 2010 \text {, de } 6 \text { de abril - Lei Orgânica do } \\
\text { Funcionamento e do Processo Legislati- } \\
\text { vo da Assembleia Nacional. }\end{array}$ \\
\hline $233 / 2013$ & 307-B/2012 & Deputados & Improcedente & $\begin{array}{l}\text { Processo de fiscalização sucessiva da } \\
\text { constitucionalidade dos decretos pre- } \\
\text { sidenciais no } 48 / 11 \text {, de } 9 \text { de março, } \\
57 / 2011 \text {, de } 30 \text { de março, e } 24 / 2012 \text {, de } \\
30 \text { de Janeiro, sobre o Fundo Petrolífero, } \\
\text { proposto pelo Grupo Parlamentar da Co- } \\
\text { ligação de Partidos Políticos CASA-CE } \\
\text { (Convergência Ampla de Salvação de } \\
\text { Angola - Coligação Eleitoral) ao Tribunal } \\
\text { Constitucional. }\end{array}$ \\
\hline $314 / 2013$ & $385-\mathrm{D} / 2013$ & OAA & $\begin{array}{l}\text { Parcialmente } \\
\text { procedente }\end{array}$ & 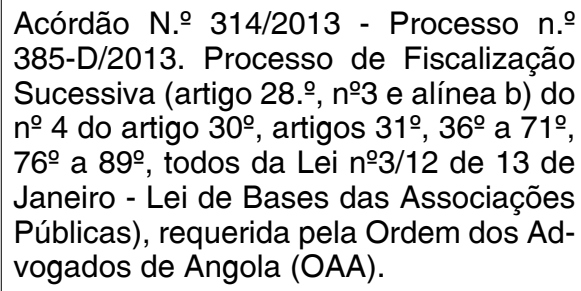 \\
\hline $319 / 2013$ & $394-C / 2013$ & Deputados & $\begin{array}{l}\text { Parcialmente } \\
\text { Procedente }\end{array}$ & $\begin{array}{l}\text { Processo de fiscalização sucessiva, re- } \\
\text { querido por vinte e dois deputados da } \\
\text { Assembleia Nacional, sobre a aprecia- } \\
\text { ção da constitucionalidade dos artigos } \\
261,268,269,270 \text { e } 271 \text {, todos do Re- } \\
\text { gimento da Assembleia Nacional apro- } \\
\text { vado pela Lei no } 13 / 2012 \text {, de } 2 \text { de maio } \\
\text { - Lei Orgânica que Aprova o Regimento } \\
\text { da Assembleia Nacional. }\end{array}$ \\
\hline $330 / 2014$ & 409-B/2014 & OAA & Improcedente & $\begin{array}{l}\text { Processo de fiscalização sucessiva de } \\
\text { constitucionalidade, requerida pela Or- } \\
\text { dem dos Advogados de Angola, das se- } \\
\text { guintes normas da Lei do Combate ao } \\
\text { Branqueamento de Capitais e do Finan- } \\
\text { ciamento ao Terrorismo, aprovada pela } \\
\text { Lei n. }-34 / 2011 \text {, de } 12 \text { de Dezembro. }\end{array}$ \\
\hline
\end{tabular}

Fonte: Tribunal Constitucional da República de Angola. 
Apesar de o presidente da República, o procurador geral da República e o ouvidor geral de Justiça poderem apresentar ação de fiscalização sucessiva, nenhuma ação proposta por esses legitimados ativos foi julgada pelo Tribunal Constitucional. De outro modo, as minorias parlamentares, por três oportunidades, e a Ordem dos Advogados de Angola, também em três ações, provocaram a atuação da corte constitucional.

A Ação de Fiscalização Sucessiva no 166/2010-D atacava o artigo 26 da Lei 7/1978, Lei dos Crimes Contra a Segurança do Estado. Trata-se de um tipo penal com extensão bastante ampla, que afirma que "todo e qualquer acto, não previsto em lei, que ponha ou possa pôr em perigo a segurança do Estado, será punido com a pena $\mathrm{n}$. 5 do art. 55 do Código Penal". Com o estabelecimento de nova lei dos crimes contra o Estado, o Tribunal Constitucional julgou improcedente a fiscalização sucessiva.

A Fiscalização Sucessiva no 173/2010 alegava a inconstitucionalidade da alínea $g$ do artigo 36 da Lei $n^{\circ} 5 / 2010$, de 6 de abril, Lei Orgânica do Funcionamento e do Processo Legislativo da Assembleia Nacional. A discussão versava sobre o funcionamento da Assembleia Nacional e as atribuições do presidente do Parlamento. Nessa ação, o tribunal votou pela constitucionalidade da norma atacada, julgando improcedente o pedido.

A Ação $\mathrm{n}^{\mathrm{o}}$ 307-B/2012 foi proposta contra os decretos presidenciais sobre o fundo petrolífero. Os parlamentares afirmavam a inconstitucionalidade dos citados decretos por afrontarem: a) poder discipli- nar da Assembleia Nacional; b) princípio da separação dos poderes; c) princípios da unidade e da diversidade orçamental; $d$ ) proibição da criação ou da modificação do fundo de petróleo pelo Executivo sem prévia autorização da Assembleia Nacional. A corte julgou improcedentes os pedidos de declaração de inconstitucionalidade, afirmando que o poder regulamentar do presidente da República para criar fundos encontra respaldo na Constituição.

Por sua vez, a Fiscalização Sucessiva de Constitucionalidade no $385-\mathrm{D} / 2013$ teve como objeto os artigos da Lei $n^{\circ} 3 / 2012$, de 13 de janeiro - Lei de Bases das Associações Públicas. O cerne de discussão, nessa ação, consiste na autonomia das associações públicas e nas intervenções inconstitucionais sobre as associações e a própria Ordem dos Advogados, abordando três principais questões: a) caráter regulamentar da lei; b) liberdade e independência do poder disciplinar; c) as ordens profissionais e tutela administrativa. Nessa referida fiscalização sucessiva, o Tribunal Constitucional julgou parcialmente os pedidos, declarando-se inconstitucionais os arts. $28,30, \mathrm{n}^{\circ} 4$, 'b', 31, 36, 37, 38, 39, 40, 41, 42, 43, 45, no $1,64^{\circ}, 76,77,78,79$ e 80.

A Ação de Fiscalização Sucessiva no 394-C/2013 aprecia a constitucionalidade dos artigos 261, 268, 269, 270 e 271 do Regimento da Assembleia Nacional, aprovado pela Lei no 13/2012, de 2 de Maio. O tema por excelência nesta fiscalização sucessiva enfrenta o poder de controle e de fiscalização da Assembleia Nacional, assim como as relações entre Executivo e Legislativo a partir da separação dos poderes. O Tri- 
bunal Constitucional julgou parcialmente procedente a ação, tendo sido declarados inconstitucionais os arts. 260, 261, no 1 e no 2, 268, 269, 270 e 271, em autuação que privilegiou a autonomia do Executivo.

$\mathrm{Na}$ Fiscalização Sucessiva $\mathrm{n}^{\circ}$ 409$\mathrm{B} / 2014$, os artigos $3^{\circ}, 2^{\circ}$, g (sujeição dos advogados a esta lei), $4^{\circ}$ ao 13 (estabelecimento de obrigações de comunicação e de identificação, verificação da identidade, obrigações de diligência, de recusa e de conservação), 15 ao 20 (obrigações de abstenção e de cooperação, dever de sigilo, proteção na prestação da informação, obrigação de controlo e de formação), 29 e 30 (obrigações de entidades não financeiras e advogados e outras profissões independentes), da Lei do Combate ao Branqueamento de Capitais e do Financiamento ao Terrorismo, aprovada pela Lei $\mathrm{n}^{\mathrm{o}} 34 / 11$, de 12 de dezembro, julgou-se improcedentes todos os pedidos feitos pela Ordem dos Advogados de Angola.

\section{Análise empírica e comparada das decisões em controle abstrato dos tribunais}

A primeira observação dos dados indica a enorme variação na quantidade de ações presentes em cada país. Os dados variam de 4.962 ADIs no Brasil a seis fiscalizações sucessivas em Angola. Isso resulta de normas sobre a admissibilidade da proposição de ações de inconstitucionalidade, da quantidade de requerentes legitimados e das restrições que esses atores possuem quanto ao escopo de temas jurisdicionáveis ao controle abstrato dos Tribunais Constitucionais, assim como do grau de institucionalização da democracia.

Além disso, para a análise comparada dos dados, como nos Tribunais Constitucionais de Portugal e de Angola somente as ações admitidas e julgadas foram acessíveis à coleta de dados, excluímos as ações que ingressaram no Supremo Tribunal Federal brasileiro e que não foram julgadas (3.616 ADI julgadas). Por fim, é relevante mencionar a inclusão, na análise dos dados, de todos os tipos de normas (legais e outros atos normativos). Ou seja, decisões parlamentares/congressuais e normas promovidas pelo Executivo e por instâncias administrativas do Judiciário.

A primeira análise comparada abordou os conflitos intraunidades julgados nos tribunais. Ou seja, aqueles em que tanto a norma questionada quanto o requerente pertenciam ao mesmo nível do Estado (federal/nacional ou regional/estadual). Os dados da Tabela 3 revelam que a judicialização de normas na esfera mais elevada (federal/nacional) apresenta resultados diversos nos países comparados. No Brasil, cerca de $1 / 3$ das ADIs julgadas (1.248 ADIs) envolveram conflitos sobre normas da União requeridas por legitimados nacionais. Entretanto, somente $15 \%$ dessas ações foram consideradas procedentes e tornaram nula (parcial ou totalmente) uma norma nacional. Caso o exame fosse restrito às normas aprovadas pelo Congresso, esse percentual se aproximaria dos $10 \%$ de normas nulificadas por ADIs. 
Tabela 3: Resultados dos julgamentos - Conflitos intraunidades

\begin{tabular}{l|c|c|c|c|c|c}
\hline \multirow{2}{*}{ País } & \multicolumn{3}{c|}{ Federal/nacional } & \multicolumn{3}{c}{ Regional/estadual } \\
\cline { 2 - 7 } & Procedente & Improcedente & $\mathrm{n}^{\circ}$ & Procedente & Improcedente & $\mathrm{n}^{\circ}$ \\
\hline Portugal & $53 \%$ & $47 \%$ & 405 & $19 \%$ & $81 \%$ & 16 \\
Brasil & $15 \%$ & $85 \%$ & 1.248 & $58 \%$ & $42 \%$ & 873 \\
Angola & $33 \%$ & $67 \%$ & 6 & -- & -- & -- \\
\hline
\end{tabular}

Fonte: Supremo Tribunal Federal; Tribunal Constitucional da República de Angola; Tribunal Constitucional de Portugal. Base de dados organizada pelos autores.

Isso indica que o processo decisório tende a absorver o STF quando o pedido de inconstitucionalidade na ADI é feito contra norma federal em conflito intraunidade. Esse aspecto é totalmente diferente no caso de Portugal, em que $4 / 5$ da fiscalização sucessiva aborda conflitos intraunidades nacionais e $53 \%$ são julgados procedentes (parcial ou totalmente). No caso de Portugal, o Tribunal Constitucional não é absorvido pela maioria parlamentar da coalizão de governo. Por sua vez, no caso de Angola, $1 / 3$ das normas em fiscalização sucessiva teve sua nulidade declarada pelo tribunal. Isso poderia indicar uma maior semelhança com o caso português. Entretanto, a quantidade exígua de processos julgados parece demonstrar que a institucionalização do controle abstrato ainda é uma via incomum para confrontar decisões da coalizão de governo.

Dessa forma, as hipóteses H1A e H1B (absorção do Tribunal Constitucional diminui a declaração de constitucionalidade) parecem ser corroboradas no Brasil, são inconclusivas em Angola e não encontram fácil demonstração nos casos de Portugal. Mensurar politicamente, e não somente institucionalmente, a absorção dos Tribunais
Constitucionais é uma tarefa em aberto nesse comparativo sobre a judicialização abstrata e concentrada.

De outro modo, há a hipótese na literatura $(\mathrm{H} 2)$ de que estados federados e unitários, com atribuição de autonomia a unidades subnacionais, utilizam judicialização abstrata em Tribunais Constitucionais como instrumento de controle legislativo sobre as unidades locais. Os Gráficos 1 e 2 permitem analisar essa questão.

Gráfico 1: Quantidade de Julgamentos - Conflitos Federativos

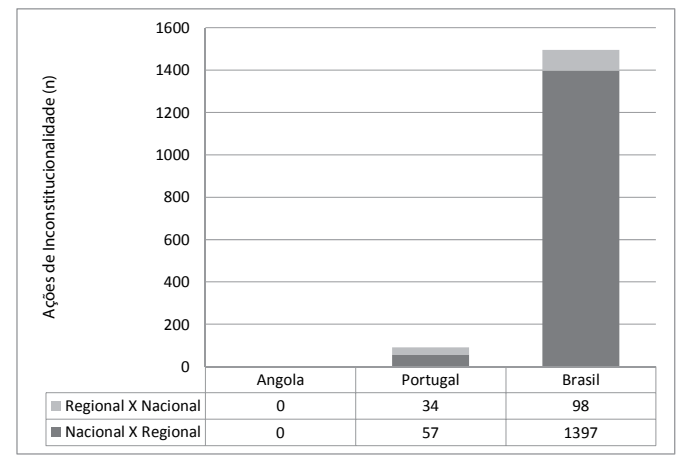

Fonte: Supremo Tribunal Federal; Tribunal Constitucional da República de Angola; Tribunal Constitucional de Portugal. Base de dados organizada pelos autores. 
Gráfico 2: Taxa de sucesso nos julgamentos - conflitos federativos

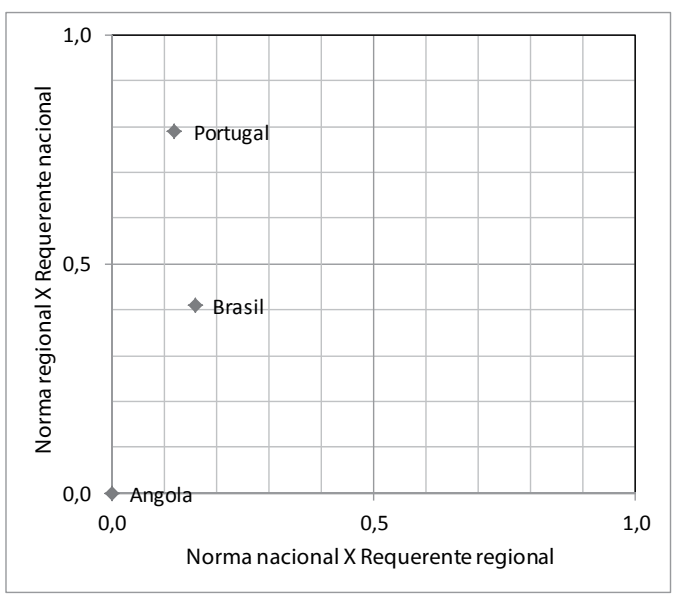

Fonte: Supremo Tribunal Federal; Tribunal Constitucional da República de Angola; Tribunal Constitucional de Portugal. Base de dados organizada pelos autores.

Ressalvada as diferenças na quantidade total de julgados em conflitos federativos em cada Tribunal Constitucional, conforme mencionado anteriormente, em Portugal há certo equilíbrio na quantidade de julgados em controle abstrato. No Brasil, as ADIs julgadas são predominantemente de legitimados nacionais contra normas estaduais. Já em Angola, sequer existe a possibilidade de julgamento de ações de legitimados locais contra normas nacionais, e nenhum legitimado nacional requereu a nulidade de alguma norma local. Possivelmente, no atual estágio de institucionalização, a capacidade política de o governo nacional controlar os governos locais prescinda de mecanismos judiciais de controle abstrato de constitucionalidade, mesmo que a Constituição angolana preveja algum grau de autonomia aos governos subnacionais.
A taxa de sucesso dos julgamentos em conflitos federativos permite dimensionar melhor o papel dos Tribunais Constitucionais (Gráfico 2). Portugal parece o estado unitário por definição. Cerca de $80 \%$ das normas locais julgadas foram declaradas parcial ou totalmente inconstitucionais pelo tribunal. De outra forma, somente cerca de $10 \%$ das demandas de legitimados das comunidades autônomas contra normas nacionais foram consideradas inconstitucionais. Índice semelhante ao encontrado para ADIs similares no Brasil (contra normas federais por iniciativa de legitimados estaduais). Porém, o STF acolheu favoravelmente somente $40 \%$ das demandas de legitimados federais contra normas estaduais.

Há algumas razões que explicam o índice brasileiro de sucesso de controle de constitucionalidade ser a metade da taxa portuguesa. Isso ocorre porque a maioria das demandas de ADIs foi proposta por organizações sociais (confederações e associações nacionais), algo que não existe similar em outros países, e partidos políticos, que conquistam baixas taxas de sucesso.

Por fim, na Tabela 4 encontram-se as taxas de sucessos no controle de constitucionalidade por requerentes, permitindo analisar o papel dos atores políticos específicos nos Tribunais Constitucionais. 
Tabela 4: Resultados dos lulgamentos - Portugal, Brasil e Angola

\begin{tabular}{|c|c|c|c|c|c|c|}
\hline \multirow{3}{*}{ Requerente/País } & \multicolumn{6}{|c|}{ Norma/resultado (\%) } \\
\hline & \multicolumn{3}{|c|}{ Nacional } & \multicolumn{3}{|c|}{ Regional } \\
\hline & Procedente & Improcedente & $\mathrm{n}^{\circ}$ & Procedente & Improcedente & $\mathrm{n}^{\mathrm{o}}$ \\
\hline NACIONAL (Portugal) & $53 \%$ & $47 \%$ & 405 & $79 \%$ & $21 \%$ & 57 \\
\hline Deputados & $31 \%$ & $69 \%$ & 52 & $75 \%$ & $25 \%$ & 8 \\
\hline Ministério Público & $89 \%$ & $11 \%$ & 28 & & & \\
\hline Presidente da Assembleia da República & $56 \%$ & $44 \%$ & 16 & $100 \%$ & $0 \%$ & 1 \\
\hline Presidente da República & $67 \%$ & $33 \%$ & 9 & & & \\
\hline Primeiro Ministro & $25 \%$ & $75 \%$ & 8 & $100 \%$ & $0 \%$ & 1 \\
\hline Procurador-Geral & $69 \%$ & $31 \%$ & 159 & $79 \%$ & $21 \%$ & 24 \\
\hline Provedor de Justiça & $34 \%$ & $66 \%$ & 133 & $73 \%$ & $27 \%$ & 11 \\
\hline Representante da República (Açores) & & & & $100 \%$ & $0 \%$ & 2 \\
\hline Representante da República (Madeira) & & & & $80 \%$ & $20 \%$ & 10 \\
\hline REGIONAL (Portugal) & $12 \%$ & $88 \%$ & 34 & $19 \%$ & $81 \%$ & 16 \\
\hline Assembleia Legislativa (Açores) & $33 \%$ & $67 \%$ & 3 & $100 \%$ & $0 \%$ & 1 \\
\hline Deputados regionais (Açores) & $0 \%$ & $100 \%$ & 4 & $25 \%$ & $75 \%$ & 4 \\
\hline Assembleia Legislativa (Madeira) & $6 \%$ & $94 \%$ & 17 & $0 \%$ & $100 \%$ & 4 \\
\hline Deputados regionais (Madeira) & $0 \%$ & $100 \%$ & 5 & $20 \%$ & $80 \%$ & 5 \\
\hline Presidente regional (Madeira) & $40 \%$ & $60 \%$ & 5 & $0 \%$ & $100 \%$ & 2 \\
\hline TOTAL (Portugal) & $49 \%$ & $51 \%$ & 439 & $66 \%$ & $34 \%$ & 73 \\
\hline NACIONAL (Brasil) & $15 \%$ & $85 \%$ & 1248 & $41 \%$ & $59 \%$ & 1397 \\
\hline Associação/Confederação & $10 \%$ & $90 \%$ & 493 & $30 \%$ & $70 \%$ & 494 \\
\hline Ordem dos Advogados do Brasil & $24 \%$ & $76 \%$ & 50 & $48 \%$ & $52 \%$ & 88 \\
\hline Partido & $8 \%$ & $92 \%$ & 461 & $32 \%$ & $68 \%$ & 264 \\
\hline Pessoa física & $0 \%$ & $100 \%$ & 42 & & & \\
\hline Presidente & $0 \%$ & $100 \%$ & 1 & $0 \%$ & $100 \%$ & 1 \\
\hline Procurador-geral da República & $44 \%$ & $56 \%$ & 201 & $55 \%$ & $45 \%$ & 549 \\
\hline Senado & & & & $100 \%$ & $0 \%$ & 1 \\
\hline ESTADUAL (Brasil) & $16 \%$ & $84 \%$ & 98 & $58 \%$ & $42 \%$ & 873 \\
\hline Assembleia & $9 \%$ & $91 \%$ & 22 & $10 \%$ & $90 \%$ & 21 \\
\hline Governador & $19 \%$ & $81 \%$ & 74 & $59 \%$ & $41 \%$ & 846 \\
\hline Município & $0 \%$ & $100 \%$ & 2 & $0 \%$ & $100 \%$ & 2 \\
\hline Pessoa física & & & & $0 \%$ & $100 \%$ & 4 \\
\hline TOTAL (Brasil) & $15 \%$ & $85 \%$ & 1346 & $47 \%$ & $53 \%$ & 2270 \\
\hline NACIONAL (Angola) & $33 \%$ & $67 \%$ & 6 & & & \\
\hline OAA (Ordem dos Advogados) & $33 \%$ & $67 \%$ & 3 & & & \\
\hline Deputados & $33 \%$ & $67 \%$ & 3 & & & \\
\hline
\end{tabular}

Fonte: Supremo Tribunal Federal; Tribunal Constitucional da República de Angola; Tribunal Constitucional de Portugal. Base de dados organizada pelos autores.

Nota: Fiscalização sucessiva (Portugal), 1983-2013, 512 ações julgadas, 11 data missing, impossível definir requerente/resultado; ADI (Brasil), 1988-2013, 3.616 ações julgadas; Controle sucessivo (Angola), 2011-2014, 6 ações julgadas. 


\section{Considerações finais}

O estudo abordou a validade empírica de duas principais hipóteses sobre o abstract judicial review, sendo a primeira hipótese desmembrada em duas sub-hipóteses, como parte do processo decisório/legislativo e seus determinantes pelo arranjo das instituições políticas e das relações entre os poderes. Os dados empíricos descritos e analisados comparam as decisões dos Tribunais Constitucionais de três países no controle concentrado/abstrato de constitucionalidade de leis, nos períodos constitucionais recentes (Brasil, Portugal e Angola). As duas hipóteses verificadas foram: 1) a proposição sobre a regra da absorção (TSEBELIS, 2009), com tribunais não atuando contramajoritariamente ao decidir sobre legislação aprovada pela coalizão majoritária; 2) nas decisões que envolvem atores de diversos níveis governamentais (BZDERA, 1993), se o controle abstrato restringe a descentralização a partir de prerrogativas consolidadas constitucionalmente pelo poder central.

A primeira observação dos dados indica a enorme variação na quantidade de ações presentes em cada país. Os dados variam de seis fiscalizações sucessivas em Angola a 4.962 ADI no Brasil. Na comparação entre Brasil e Portugal, isso resulta de normas sobre a admissibilidade da proposição de ações de inconstitucionalidade, da quantidade de requerentes legitimados e das restrições que esses atores têm quanto ao escopo de temas jurisdicionáveis ao controle abstrato dos Tribunais Constitucionais.

De outro modo, Angola viveu intensa guerra civil, de 1975 a 2002, sendo sua Cons- tituição vigente datada de 2010. O estabelecimento recente das estruturas do estado democrático de direito em Angola explica parcialmente a pequena quantidade de fiscalizações sucessivas.

As hipóteses somente poderiam ser claramente dimensionadas tendo em vista a variação política e eleitoral do processo de nomeação dos juízes em Tribunais Constitucionais. Infelizmente, os dados disponíveis no momento não tornam possível essa verificação plena para todos os tribunais, governos e parlamentos. Isso indica que, sem variáveis políticas e eleitorais que tornem mais elucidativas a análise, não é possível dimensionar completamente a eficácia da regra da absorção nesses países.

Dessa forma, as hipóteses H1A e H1B (regra da absorção) parecem ser corroboradas no Brasil e, dadas as circunstâncias institucionais, em Angola, não encontram fácil demonstração nos casos de Portugal. Mensurar politicamente, e não somente institucionalmente, a absorção dos Tribunais Constitucionais é uma tarefa em aberto nesse comparativo sobre a judicialização abstrata e concentrada. De outra forma, os Estados, independentemente se federados ou unitários, como Brasil e Portugal, ao atribuir autonomia às unidades subnacionais, utilizam a judicialização abstrata em tribunais constitucionais como instrumento de controle legislativo sobre as unidades locais, considerando válida a $\mathrm{H} 2$ nesses dois países. 


\section{Abstract}

The paper analyses empirically and comparatively the decisions of the Constitutional Courts of Portugal, Angola and of the Supreme Federal court in concentrated and abstract judicial review. The study verifies the empirical validity of two hypotheses over abstract judicial review: 1) the proposition over the rule of absorption (TSEBELIS, 2009), that courts do not act contramajoritarilly in deciding over legislation approved by a majority coalition; and 2) in decisions that involve agents in various governmental levels (BZDERA, 1993), if abstract review restricts decentralization through constitutionally prerogatives consolidated by the central power. Preliminary conclusions indicate empirical validity in the first hypothesis for Brazil and in the second hypothesis for Brazil and Portugal. In Angola, the second hypothesis has no validity.

Keywords: Comparative Judicialization of Politics. Constitutional Jurisdiction. Concentrated/Abstract Judicial Review.

\section{Resumen}

Esto trabajo analiza empírica y comparativamente las decisiones de los Tribunales Constitucionales de Portugal y Angola y de lo Supremo Tribunal Federal en lo controle concentrado/abstracto. El estudio verifica la validad empírica de dos hipótesis sobre lo abstract judicial review: 1) la proposición sobre la regla de absorción (TSEBELIS, 2009), con tribunales no actuando contra-mayoritariamente cuando deciden sobre legislación aprobada por la coalición mayoritaria; y 2) en las decisio- nes que recaen sobre actores de diversos niveles gubernamentales (BZDERA, 1993), se lo control abstracto restringe la des-centralización por prerrogativas consolidadas constitucionalmente por lo poder central. Conclusiones preliminares indican validad empírica en la primera hipótesis para Brazil y en la segunda hipótesis para Brazil e Portugal. En Angola, la segunda hipótesis es completamente negada.

Palabras clave: Judicialización de la Política Comparada. Jurisdicción Constitucional. Control Concentrado/Abstracto de Constitucionalidad.

\section{Notas}

1 A pesquisa e a coleta de dados para este artigo foi realizada pelos membros do Núcleo de Pesquisa DIRPOL-Direito e Política (PPGD/UFPR) com o financiamento do CNPq/Capes (Edital 07/2011).

2 Para um panorama sobre as diversas interpretações sobre as instituições sociais e jurídicas brasileiras, as quais apontam inúmeras influências das instituições portuguesas no Brasil, cf. Botelho e Schwarcz (2009).

3 Sobre o processo da construção de instituições democráticas a partir do último quarto do século XX e do papel dos poderes Legislativo, Executivo e Judiciário, cf. O'Donnell $(1998,2009)$.

4 Apesar de o Supremo Tribunal Federal brasileiro não se constituir em um Tribunal Constitucional pleno nos termos do modelo europeu de controle judicial de constitucionalidade, em virtude de: a) exercer controle abstrato e concentrado de constitucionalidade; b) ser o principal guardião da Constituição dentre os poderes instituídos, para fins deste estudo considerar-se-á o STF um Tribunal Constitucional.

5 Utiliza-se neste artigo o conceito de veto advindo do campo da ciência política e, especialmente, da obra de Tsebelis (2009). Entende-se por poder de veto a competência de um ator político e jurídico de rever uma decisão tomada por outros atores, impossibilitando a sua implantação.

6 A elevada absorção do Supremo Tribunal Federal brasileiro dá-se por somente o Presidente da República poder indicar seus membros e o Senado Federal confirmá-lo por maioria simples. Assim 
é difícil que a minoria parlamentar impossibilite a investidura de jurista próximo do Executivo federal e da coalização majoritária do Senado. De outro modo, em Angola, o elevado grau de absorção ocorre principalmente pelo Presidente da República indicar quatro membros sem qualquer controle de outro ator político ou social.

7 Como há maior literatura sobre o controle judicial de constitucionalidade no Brasil e em Portugal, assim como em virtude da pequena quantidade de casos analisados pelo Tribunal Constitucional de Angola, optou-se por uma análise mais descritiva do abstract judicial review em Angola.

\section{Referências}

ANGOLA. Constituição da República de Angola de 2010. Promulgada em 5 de fevereiro de 2010. Disponível em : <http://www.tribunalconstitucional.ao/uploads/\%7B9555c635-8d7c-4ea1-b7f9-0cd33d08ea40\%7D.pdf>. Acesso em: 15 abr. 2015.

. Tribunal Constitucional da República de Angola. Acórdãos. Disponível em: <http:/ / www. tribunalconstitucional.ao/Conteudos/Artigos/ lista_artigos.aspx?idc $=152 \& \mathrm{idsc}=167 \& \mathrm{idl}=1>$. Acesso em: 10 de abril 2015.

BZDERA, A. Comparative analysis of federal high courts: a political theory of judicial review. Canadian Journal of Political Science, v. 26, p. 1, mar. 1993.

BRASIL. Constituição da República Federativa do Brasil de 1988. Promulgada em 5 de outubro de 1988. Disponível em: <http://www.planalto. gov.br/ccivil_03/constituicao/constituicao. htm >. Acesso em: 15 abr. 2015.

BRASIL. Supremo Tribunal Federal. Processos: ADI, ADC, ADO e ADPF. Disponível em: <http://www.stf.jus.br/portal/peticaoInicial/pesquisarPeticaoInicial.asp>. Acesso em: 30 mar. 2014.

CARVALHO, E. R. Judicialização da política no Brasil: controlo de constitucionalidade e racionalidade política. Análise social, Lisboa, n. 191, abr. 2009.

CORKIN, N. C. Developments in abstract judicial review in Austria, Italy and Germany. 2010. Tese
(Doutorado em Department of Political Science) University of Birmingham. Birmingham, 2010.

PORTUGAL. Constituição da República Portuguesa de 1976. Promulgada em 2 de abril de 1976. Disponível em: < http:/ / www.tribunalconstitucional.pt/tc/crp.html>. Acesso em: 18 de março 2015.

Tribunal Constitucional. O que é, pra que serve, como funciona. Disponível em: <http:/ / www.tribunalconstitucional.pt/tc/content/ files/tc_ebook_30anos/index.html\#28/z>. Acesso em: 20 mar. 2015.

Tribunal Constitucional. Jurisprudência. Disponível em: <http://www.tribunalconstitucional.pt/tc/acordaos/>. Acesso em: 28 abr. 2014. FIGUEROA, Julio Rios; TAYLOR, Mattew. Institutional determinants of the judicialization of policy in Brazil and Mexico. Journal latin american studies, v. 38, p. 739-66. 2006.

TAYLOR, Mattew; DA ROS, Luciano. Os partidos dentro e fora do poder: a judicialização como resultado contingente da estratégia política. Dados, v. 51, n. 4.2008.

TOMIO, Fabricio Ricardo de Lima; ROBL Filho, Ilter Norberto. Empirical legal studies: teoria e metodologia para a abordagem do processo decisório de controle de constitucionalidade no STF. In: VESTENA, C. A.; SIQUEIRA, G. S. Direito e experiências jurídicas: debates práticos. Belo Horizonte: Arraes Editores, 2013. p. 96-117. TSEBELIS, George. Poder Judiciário e burocracias. In: TSEBELIS, G. Atores com poder de veto. Rio de Janeiro: FGV, 2009.

VANBERG, Georg. Abstract judicial review, legislative bargaining, and policy compromise. Journal of theoretical politics, v. 10, n. 3, p. 299327. 1998.

. Legislative-judicial relations: a game-theoretic approach to constitutional review. American journal of political science, v. 45, n. 2, p. 346-361. apr. 2001.

VIANNA, L. W.; BURGOS, M. B.; SALLES, P. M. Dezessete anos de judicialização da política. Tempo social, v. 19, n. 2, nov. 2007. 